\title{
Article
}

\section{The Influence of Minimalist Footwear on Knee and Ankle Load during Depth Jumping}

Sinclair, Jonathan Kenneth, Hobbs, Sarah Jane and Selfe, James Available at http://clok.uclan.ac.uk/11944/

Sinclair, Jonathan Kenneth ORCID: 0000-0002-2231-3732, Hobbs, Sarah Jane ORCID: 0000-0002-1552-8647 and Selfe, James (2015) The Influence of Minimalist Footwear on Knee and Ankle Load during Depth Jumping. Research in Sports Medicine, 23 (3). ISSN 1543-8627

It is advisable to refer to the publisher's version if you intend to cite from the work. http://dx.doi.org/10.1080/15438627.2015.1040917

For more information about UCLan's research in this area go to http://www.uclan.ac.uk/researchgroups/ and search for <name of research Group>.

For information about Research generally at UCLan please go to http://www.uclan.ac.uk/research/

All outputs in CLoK are protected by Intellectual Property Rights law, including Copyright law. Copyright, IPR and Moral Rights for the works on this site are retained by the individual authors and/or other copyright owners. Terms and conditions for use of this material are defined in the policies page.

\section{CLoK}

Central Lancashire online Knowledge www.clok.uclan.ac.uk

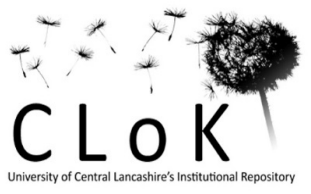




\title{
The Influence of Minimalist Footwear on Knee and Ankle Load during Depth Jumping
}

\author{
J. SINCLAIR, S.J. HOBBS, and J. SELFE \\ Centre for Applied Sport and Exercise Sciences, School of Sport Tourism and Outdoors, \\ University of Central Lancashire, UK
}

\begin{abstract}
Plyometric training is used by atbletes to promote strength and explosive power. However plyometric activities such as depth jumping are associated with a high incidence of injuries. This study examined the influence of minimalist and conventional footwear on the loads experienced by the patellofemoral joint and Achilles tendon. Patellofemoral and Achilles tendon forces were obtained from ten male participants using an eight-camera 3D motion capture system and force platform data as they completed depth jumps in both footwear conditions. Differences between footwear were calculated using paired t-tests. The results show that the minimalist footwear were associated with significantly lower patellofemoral contact force/pressure and also knee abduction moment. It is therefore recommended, based on these observations, that those who are susceptible to knee pain should consider minimalist footwear when performing plyometric training.
\end{abstract}

KEYWORDS Ldepth jump, patellofemoral pain, Achilles tendon

\section{INTRODUCTION}

Plyometric training is used by athletes to promote strength and explosive power (Chu, 1998). Depth jumping is a fundamental plyometric activity (McClenton, Brown, Coburn, \& Kersey, 2008), and involves dropping from plyometric boxes of different heights then performing a maximal vertical jump immediately upon

Received 8 July 2014; accepted 27 December 2014.

Address correspondence to Jonathan Sinclair, Division of Sport, Exercise and Nutritional Sciences, Centre for Applied Sport and Exercise Sciences, University of Central Lancashire, Preston, Lancashire PR1 2HE, UK. E-mail: Jksinclair@uclan.ac.uk 
landing (Hortobagyi, Havasi, \& Varga, 1990). Plyometric movements utilize the rapid shortening of the muscle brought about by a prior eccentric stretch, known as the stretch-shortening cycle (Markovic, 2007). The elastic energy that is stored within the muscle as a function of the landing phase is utilized to produce more force during the jump phase than would be possible during a concentric action alone (Miller, Herniman, Ricard, Cheatham, \& Michael, 2006).

However, jump landing activities are associated with rapid decelerations and the loads imposed upon specific musculoskeletal structures can be associated with the occurrence of trauma (Aerts, Cumps, Verhagen, Verschueren, \& Meeusen, 2013). Jump landing actions have been associated with a number of injuries such as stress fractures (Romani, Gieck, Perrin, Saliba, \& Kahler, 2002), tendinopathy (Rutland et al., 2010), patelloremoral pain (Waryasz \& McDermott, 2008) and anterior cruciate ligament tears (Hewett, Foed, Hoogenboom, \& Myer, 2010) and ankle sprains (Saluta \& Nunley, 2010). Patellofemoral pain is the most common chronic pathology in athletic populations (Davis \& Powers 2010) and its aetiology is linked to habitual and excessive patellofemoral joint loading (Ho, Blanchette, \& Powers, 2012). Patellofemoral disorders are associated with high impact physical activities such as depth jumping, which utilize high levels of knee flexion (Crossley, Bennell, Green, Cowan, \& McConnell, 2002; Witvrouw et al., 2013). In addition to this, injury to the Achilles tendon is also common in active populations (de Jonge et al., 2011). The Achilles tendon experiences large forces AQ1 during the landing phase of jumping activities (Self \& Pain, 2000), which have been linked to the development of pathology of the tendon itself (Burgess, Connick, Graham-Smith, \& Pearson, 2007; Wu et al., 2009).

In recent years, there has been a trend towards athletes performing their plyometric activities barefoot or in minimalist footwear in lieu of conventional athletic footwear (LaPorta et al., 2013). Training barefoot is now extremely popular and has received extensive attention in both research and clinical settings (De Wit, De Clercq, \& Aerts, 2000; Divert, Mornieux, Baur, Mayer, \& Belli, 2005; Divert, et al., 2008; Gruber, Silvernail, Brueggemann, Rohr, \& Hamill, 2013; Hamill, Russell, Gruber, \& Miller, 2011; Hanson, Berg, Deka, Meendering, \& Ryan, 2011; Lieberman et al., 2010; Nigg 2009; Sinclair, Greenhalgh, Edmundson, Brooks, \& Hobbs, 2013; Sinclair, Hobbs, Currigan, \& Taylor, 2013; Squadrone \& Gallozzi, 2009; Stacoff, Nigg, Reinschmidt, van den Bogert, \& Lundberg, 2000). Taking into account the popularity of barefoot training, minimalist footwear has been designed with the goal of replicating the potential benefits of training barefoot (Sinclair, Greenhalgh, Edmundson, Brooks, \& Hobbs, 2013; Sinclair, Hobbs, Currigan, \& Taylor, 2013). Only one study to date has investigated the influence of barefoot and minimalist footwear on the biomechanics of the depth jump. LaPorta et al. (2013) demonstrated that there were no significant differences in peak power production and jump height between barefoot, minimalist and conventional footwear during the depth jump movement. 
There is a paucity of information regarding the influence of minimalist footwear on the loads experienced by the knee and ankle during plyometric activities. The effects of different footwear on knee and ankle loads have, however, been examined previously during running activities. Bonacci, Vicenzino, Spratford, and Collins (2013) examined the effects of barefoot and shod running on patellofemoral loading the stance phase. They showed that both patellofemoral contact force $(P T C F)$ and pressure $(P T C P)$ were significantly reduced when running barefoot compared with wearing shoes. In addition, Sinclair (2014) measured PTCF, PTCP and Achilles tendon loads ( $A T L)$ when running barefoot and wearing barefoot-inspired shoes in relation to conventional footwear. It was demonstrated that whilst PTCF and PTCP were reduced in the barefoot and minimalist conditions, the $A T L$ was correspondingly increased. The proposed relationship between patellofemoral loading and the initiation of patellofemoral disorders indicates that minimalist footwear may have the potential to reduce the incidence of injury. However, despite the frequent utilization of minimalist footwear for plyometric activities, it is not known whether reductions in joint loading found during running are transferable to activities such as depth jumping.

The aim of the current investigation was therefore to determine whether depth jumping whilst wearing minimalist footwear caused different levels of PTCF and PTCP at the knee and ATL at the ankle in comparison $\Delta^{\text {with }}$ conventional trainers. A study of this nature may provide important clinical information regarding the effects of different footwear on the loads experienced by specific musculoskeletal structures shown to be susceptible to injury as a result of plyometric activities. Specifically, it was hypothesized that performing depth jumps in minimalist footwear would be associated with reduced loads at the knee comparison _with wearing conventional trainers.

\section{METHODS}

\section{Participants}

Ten male participants (age $22.38 \pm 4.47$ years; height $1.73 \pm 0.07 \mathrm{~m}$; mass $67.83 \pm 5.65 \mathrm{~kg}$ ) took part in the current study. Participants all had previous experience of performing plyometric activities as part of their training regime. Ethical approval for this project was obtained from the University ethics committee, and each participant provided informed consent in written form in accordance with the declaration of Helsinki.

Procedure

Each participant completed a warm-up protocol that included 90 seconds of cycling on a cycle ergometer (Monark 828E, Monark Exercise AB, Sweden) 
and 90 seconds of step-ups onto a $30 \mathrm{~cm}$ box in accordance with Smith, Kernozek, Kline, \& Wright (2011). Kinematic information was captured at 250 $\mathrm{Hz}$ using an eight-camera optoelectric motion analysis system (Qualisys Medical AB, Goteburg, Sweden). Calibration of the system was performed before each data collection session. To measure angular kinematics at the knee and ankle the principles of a calibrated anatomical systems technique (Cappozzo, Catani, Leardini, Benedeti, \& Della, 1995) were utilized. In order

AQ2 to define the anatomical frames of the right; foot, shank and thigh, retroreflective markers (19 $\mathrm{mm}$ diameter) were positioned unilaterally to the calcaneus, first and fifth metatarsal heads, medial and lateral malleoli and medial and lateral epicondyles of the femur. Tracking clusters were also positioned onto the shank and thigh segments. The foot segment was tracked using the finst and fifth metatarsal markers respectively. Static trials were conducted allowing the positions of the anatomical markers to be referenced in relation to the tracking markers/clusters, following which those not required for tracking were removed.

All participants completed a total of five depth jumps in each footwear condition. The order in which participants performed depth jumps in each footwear was randomized. This involved stepping from a $40 \mathrm{~cm}$ box (Gehri, Ricard, Kleiner, \& Kirkendall, 1998), and landing onto a piezoelectric force platform (Kistler Instruments Ltd., Alton, Hampshire, UK) positioned $30 \mathrm{~cm}$ in front of the platform (Smith et al., 2011).

\section{Data Processing}

Ground reaction force and kinematic data were smoothed using cut-off frequencies of $50 \mathrm{~Hz}$ and $10 \mathrm{~Hz}$ with a low-pass Butterworth founth-order filter using Visual 3-D (C-Motion, Germantown, MD, USA). Newton-Euler inverse-dynamics were used, which allowed knee joint moments ( $\mathrm{Nm}_{\curlywedge} \mathrm{kg}$ ) to be calculated. To quantify net joint moment's segment mass, segment length, GRF and angular

AQ3 kinematics were utilized using the procedure described by Selbie et al. (2014). Knee loading was examined through extraction of a peak knee extensor moment, patellofemoral contact force $(P C F)$ and patellofemoral contact pressure $(P P)$.

A previously utilized algorithm was used to quantify $P C F$ and $P P$ (Ward \&

Aq4 Powers, 2004). This method has been utilized previously to resolve differences in $P C F$ and $P P$ when using different footwear (Bonacci et al., 2013; Kulmala, Avela, Pasanen, \& Parkkari, 2013; Sinclair, 2014) and between those with and without patellofemoral pain (Heino \& Powers, 2002). PTCF (B.W) was estimated using knee flexion angle (KFA) and knee extensor moment (KEM) through the biomechanical model of Ho et al. $(2012)$. The moment arm of the quadriceps ( $Q M A)$ was calculated as a function of $K F A$ using a nonlinear equation, based on cadaveric information presented by van Eijden, Kouwenhoven, Verburg, \& Weijs (1986): 


$$
\mathrm{QMA}=0.00008 K F A^{3}-0.013 K F A^{2}+0.28 K F A+0.046
$$

Quadriceps force $(F Q)$ was calculated using the below formula:

$$
\mathrm{FQ}=K E M / Q M A
$$

$P T C F$ was estimated using the $F Q$ and a constant $(C)$ :

$$
P T C F=F Q C
$$

The $C$ was described in relation to KFA using the equation described by van AQ5 Eijden et al, $(2012)$ :

$$
\begin{aligned}
\mathrm{C}= & \left(0.462+0.00147 K F A^{2}-0.0000384 K F A^{2}\right) / \\
& \left(1-0.0162 K F A+0.000155 K F A^{2}-0.000000698 K F A^{3}\right)
\end{aligned}
$$

PTCP (MPa) was calculated using the PTCF divided by the patellofemoral contact area. The contact area was delineated by fitting a second-order polynomial curve to the data of Powers, Lilley, \& Lee (1998) showing patellofemoral contact areas at varying levels of KFA $\left(83 \mathrm{~mm}^{2}\right.$ at $0^{\circ}, 140 \mathrm{~mm}^{2}$ at $15^{\circ}$, $227 \mathrm{~mm}^{2}$ at $30^{\circ}, 236 \mathrm{~mm}^{2}$ at $45^{\circ}, 235 \mathrm{~mm}^{2}$ at $60^{\circ}$, and $211 \mathrm{~mm}^{2}$ at $75^{\circ}$ ).

$$
P T C P=P T C F / \text { contact area }
$$

To estimate Achilles tendon kinetics, a predictive algorithm was utilized (Self AQ6 \& Pain 2001). Achilles tendon load (ATL) was determined by dividing the plantarflexion moment (PFM) by the estimated Achilles tendon moment arm (atMA). The moment arm was quantified as a function of the ankle sagittal plane ankle angle $(S A A)$.

$$
\begin{gathered}
A T L=P F M / \text { atMA } \\
\text { atMA }=-0.5910+0.08297 \mathrm{SAA}-0.0002606 \mathrm{SAA}^{2}
\end{gathered}
$$

\section{Experimental Footwear}

The training shoes used during the current investigation consisted of conventional footwear (New balance 1260) and minimalist footwear (Vibram fivefingers) (shoe size 8-10 UK men's). 


\section{Statistical Analyses}

Differences in patellofemoral and Achilles tendon loads as a function of footwear were examined using paired samples t-tests. The alpha criterion for statistical significance was adjusted to $p=0.008$ using a Bonferroni correction to control type I error. Effect sizes were calculated using a Cohen's D. All statistical analyses were conducted using SPSS 21.0 (SPSS Inc., Chicago, USA).

\section{RESULTS}

Figures 1 and 2 present the knee and ankle joint kinetics/kinematics obtained as a function of footwear, and Table 1 exhibits the discrete knee and ankle joint kinetic parameters. The results indicate that whilst the kinetic/kinematics curves were quantitatively similar, the experimental footwear significantly influenced knee kinetic parameters during the depth jump.

\section{Knee Loads}

Minimalist footwear were associated with a significantly lower peak KEM $\left(t_{(11)}=6.24, p<0.008, D=3.76\right)$ (Table 1: Figure $1 \mathrm{~b}$ ). In addition PTCF $\left(t_{(11)}=6.89, p<0.008, D=4.15\right)$ and PTCP $\left(t_{(11)}=6.97, p<0.008\right.$, $D=4.20$ ) were also shown to be significantly lower in minimalist footwear (Table 1: Figures 1c,d). Finally the minimalist footwear were associated with a significantly $\left(t_{(11)}=4.86, p<0.008, D=2.93\right)$ lower peak coronal knee moment (Table 1: Figure 1e).

\section{Ankle Loads}

No significant $(p>0.008)$ differences in ankle joint kinetics were observed between footwear (Table 1: Figures 1b,c).

\section{DISCUSSION}

The current investigation aimed to determine the effects of minimalist and conventional footwear on PTCF and PTCP at the knee and ATL at the ankle. This represents the first investigation to examine the influence of minimalist and conventional footwear on the loads experienced by specific musculoskeletal structures. A study of this nature may provide clinical information regarding the influence of different footwear on the loads experienced by different musculoskeletal structures during plyometric activities.

In support of the hypothesis, the current investigation showed that 

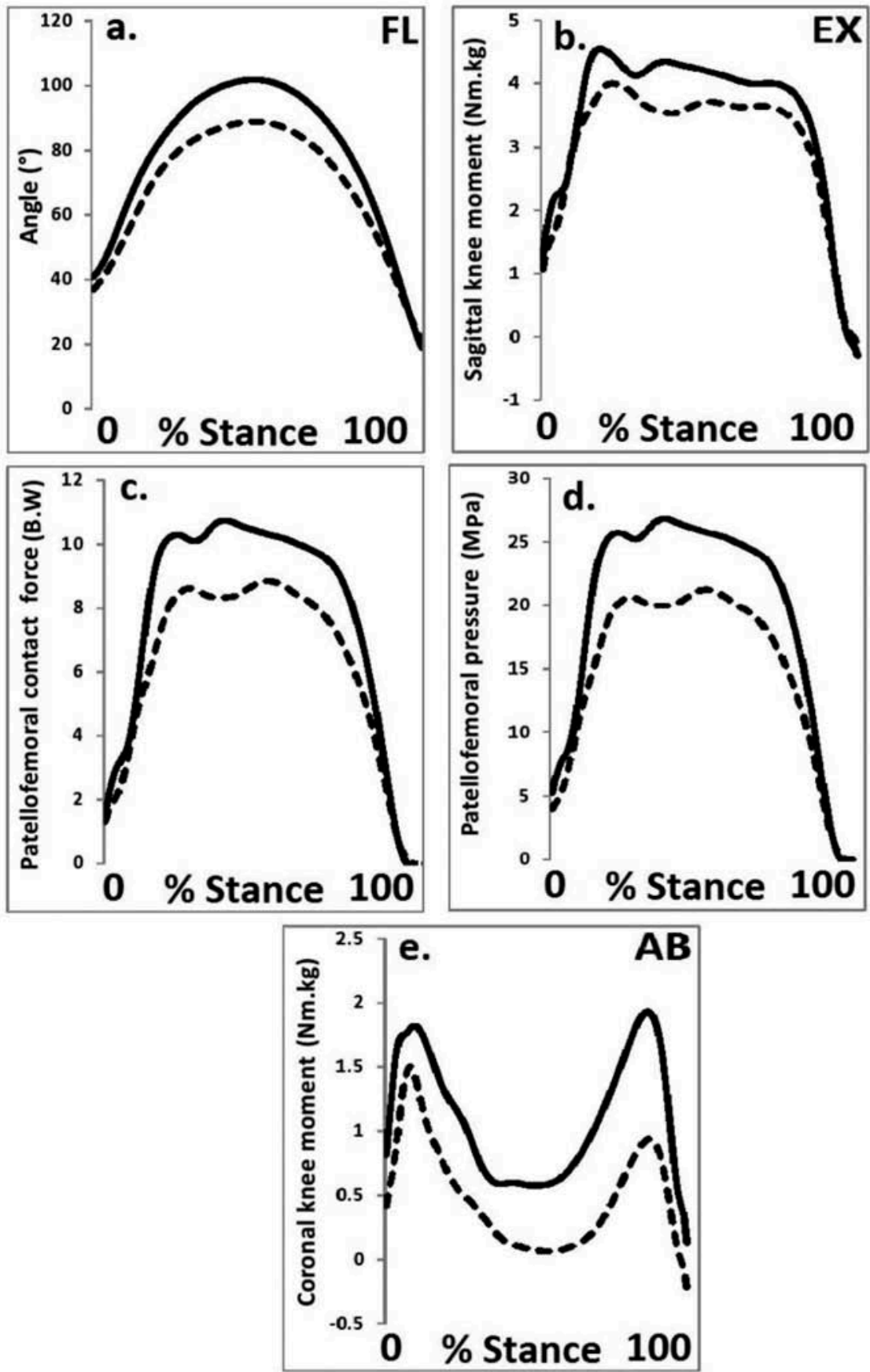

FIGURE 1 Knee kinetics and kinematics as a function of footwear, black = conventional, Dash $=$ minimalist $(\mathrm{a}=$ sagittal knee angle, $\mathrm{b}=$ sagittal knee moment, $\mathrm{c}=P T C F, \mathrm{~d}=P T C P, \mathrm{e}=$ coronal knee moment). 

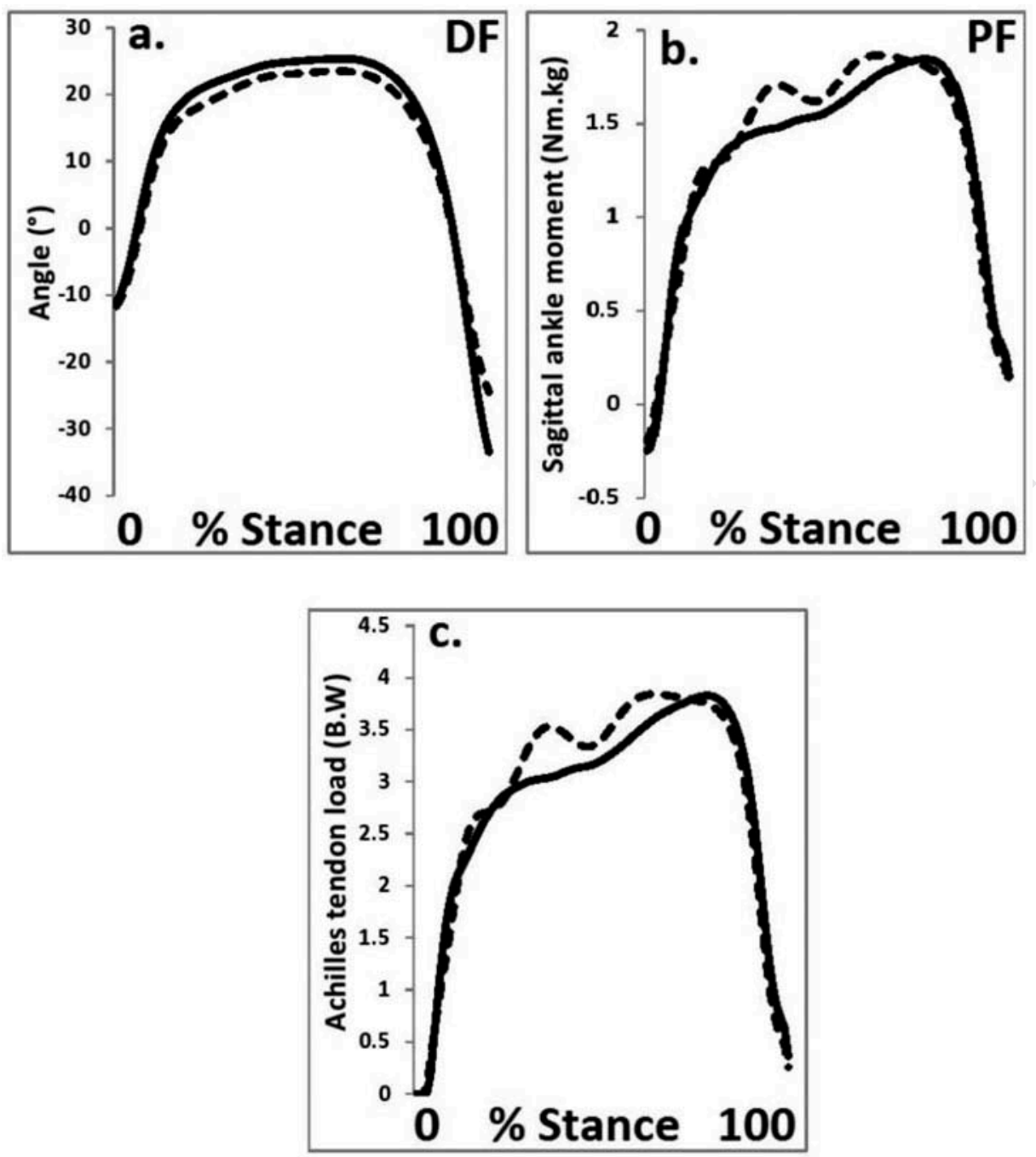

FIGURE 2 Ankle kinetics and kinematics as a function of footwear, black = conventional, Dash $=$ minimalist $(\mathrm{a}=$ ankle angle, $\mathrm{b}=$ sagittal ankle moment, $\mathrm{c}=\mathrm{ATF})$.

and PTCP _compared ${ }_{\text {with }}$ conventional shoes. This observation concurs with that of Sinclair (2014), who showed that PTCF and PTCP were significantly reduced during barefoot and minimalist conditions compared _with traditional footwear during running. However, the percentage decreases in PTCF and PTCP observed in the current study were larger than those noted by Sinclair (2014), of 16.55 and $9.05 \%$ respectively. A further important finding from this study is that depth jumping in conventional footwear was associated with significant increases in peak knee abduction moment compared owith the minimalist shoes. 
TABLE 1 Mean and SD, Joint Kinetic Information as a Function of Footwear

\begin{tabular}{|c|c|c|c|c|c|}
\hline & \multicolumn{2}{|c|}{ Minimalist } & \multicolumn{2}{|c|}{ Conventional } & \multirow{2}{*}{$\begin{array}{c}\text { Percentage } \\
\text { difference }\end{array}$} \\
\hline & Mean & $\mathrm{SD}$ & Mean & SD & \\
\hline Peak KEM (Nm kg) & 3.94 & 0.94 & 4.66 & 1.02 & $15.45^{*}$ \\
\hline$P T C F(\mathrm{~B} \mathrm{~W})$ & 8.56 & 1.68 & 10.84 & 1.75 & $21.03^{*}$ \\
\hline$P T C P(\mathrm{MPa})$ & 20.83 & 3.25 & 26.71 & 3.08 & $22.01 *$ \\
\hline Peak coronal knee moment (Nm kg) & 1.51 & 0.35 & 1.96 & 0.37 & $22.96^{*}$ \\
\hline Peak PFM (Nm.kg) & 1.84 & 0.14 & 1.82 & 0.16 & 1.10 \\
\hline$A T L(\mathrm{~B} . \mathrm{W})$ & 3.81 & 0.24 & 3.79 & 0.35 & 0.53 \\
\hline
\end{tabular}

Notes: $*$ significant difference $(\mathrm{p}<0.008)$.

On the basis that increases in PTCF, PTCP and peak abduction moment were observed in the conventional footwear, the results from the current study may provide evidence to support the utilization of minimalist footwear for depth jumping. The development of patellofemoral pain is considered to be related to excessive patellofemoral joint stress (Ho et al., 2012). In addition, increases in peak knee abduction moments have been positively associated with increases in medial compartment loading and increased stress loading of Aq7 the lateral facet of the patellofemoral joint (Sigward et al., 2013; Zhao et al., 2007). However, these observations must be contextualized by taking into account the decreased loading frequency during plyometric training compared Lwith activities such as running (Piper \& Erdmann, 1998). Therefore, although the magnitudes PTCF, PTCP and peak abduction are larger than those observed during running, the amount of cumulative stress is lower, as the total number of loading cycles is much larger in running activities (Liebermann et al., 2010). There is currently a lack of epidemiological information regarding the effects of cumulative and singular loads experienced by the lower extremities during running. Therefore, future work is required before claims regarding injury prevention in minimalist footwear can be made.

It was also shown that the $A T L$ did not differ significantly between footwear. This observation disagrees with that of Sinclair (2014) who showed that during running, barefoot and minimalist footwear were associated with significant increases in $A T L$ parameters comparison jwith conventional trainers. It is likely that this observation relates to the similar ankle kinematics that were observed between footwear (Figure 2a), indicating that the moment arm of the tendon

AQ8 remains relatively constant between footwear (Self \& Pain 2000). Thus, the force experienced by the tendon is likely to be minimally different between footwear conditions. On the basis of the observations from the current investigation it can be concluded that minimalist footwear does not offer any benefits in terms of protection from injury to the Achilles tendon. 
A potential limitation of the current investigation is that only male participants were examined. Recreationally active females are considered to be at much greater risk of developing patellofemoral pain than jage-matched males (Robinson \& Nee, 2007). Females are associated with different landing mechanics during plyometric jumping activities (Hewett, Stroupe, Nance, \& Noyes, 1996) and LaPorta et al. (2013) _documented that females exhibited distinct responses to different footwear during plyometric activities, indicating that the results from the current study cannot be generalized to females. Therefore, it may be prudent for future work to repeat the current investigation using a female sample. A further limitation is that a predictive algorithm was utilized to measure patellofemoral forces. Shisis, however, was unavoidable, as taking direct measures of patellofemoral kinetics is not possible due to ethical considerations. Nonetheless, this procedure may have underestimated the magnitudes of PTCF and PTCP, as sagittal knee moments served as the main input parameter, which does not take into consideration the antagonist muscle force generation that acts in the opposing direction of the knee joint.

In conclusion, the present study adds to the current knowledge regarding the influence of different footwear on the loads experienced by the knee and ankle. Given that significant reductions in patellofemoral load parameters were noted in the minimalist footwear, it can be concluded that they may be associated with a reduced injury risk at the knee. It is recommended based on these findings that those utilizing depth jumping as part of their training, who are susceptible to knee pain, should consider minimalist footwear in order to attenuate the risk factors associated with chronic injury aetiology.

\section{DISCLOSURE STATEMENT}

No potential conflict of interest was reported by the authors.

University's Code of Conduct for Research can be found at the following web address:

http://www.uclan.ac.uk/information/research/research_degrees/ethics_re search_governance.php.

\section{REFERENCES}

Aerts, I., Cumps, E., Verhagen, E., Verschueren, J., \& Meeusen, R. (2013). A systematic review of different jump-landing variables in relation to injuries. Journal of Sports Medicine and Physical Fitness, 53, 509-519.

Bonacci, J., Vicenzino, B., Spratford, W., \& Collins, P. (2013). Take your shoes off to reduce patellofemoral joint stress during running. British Journal of Sports Medicine. Epub ahead of print: doi:10.1136/bjsports-2013-092160. 
Burgess K.E., Connick, M.J., Graham-Smith, P., \& Pearson, S.J. (2007). Plyometric vs. isometric training influences on tendon properties and muscle output. Journal of Strength and Conditioning Research, 21, 986-989.

Cappozzo, A., Catani, F., Leardini, A., Benedeti, M.G., \& Della, C.U. (1995). Position and orientation in space of bones during movement: Anatomical frame definition and determination. Clinical Biomechanics, 10, 171-178.

Crossley, K., Bennell, K., Green, S., Cowan, S., \& McConnell, J., (2002). Physical therapy for patellofemoral pain: a randomized, double blinded, placebo-controlled trial. The American Journal of Sports Medicine, 30, 857-865.

Chu, D.A. (1998) Jumping into plyometrics. Champaign, IL: Human Kinetics.

Davis, I.S., \& Powers, C. (2010). Patellofemoral Pain Syndrome: Proximal, Distal, and Local Factors-International Research Retreat, April 30-May 2, 2009, Baltimore, Maryland. Journal of Orthopaedic and Sports Physical Therapy, 40, 1-48.

de Jonge, S., Van den Berg, C., De Vos, R.J., Van der Heide, H.J L., Weir, A., Verhaar, J.A. N., \& Tol, J.L. (2011). Incidence of midportion Achilles tendinopathy in the general population. British Journal of Sports Medicine, 45, 1026-1028.

De Wit, B., De Clercq, D., \& Aerts, P. (2000). Biomechanical analysis of the stance phase during barefoot and shod running. Journal of biomechanics, 33, 269-278.

Divert, C., Mornieux, G., Baur, H., Mayer, F., \& Belli, A. (2005). Mechanical comparison of barefoot and shod running. International Journal of Sports Medicine, 26, 593-598.

Divert, C., Mornieux, G., Freychat, P., Baly, L., Mayer, F., \& Belli, A. (2008). Barefootshod running differences: shoe or mass effect? International Journal of Sports Medicine, 29, 512-518.

Gehri, D.J., Ricard, M.D., Kleiner, D.M., \& Kirkendall, D.T. (1998). A comparison of plyometric training techniques for improving vertical jump ability and energy production. The Journal of Strength \& Conditioning Research, 12, 85-89.

Gruber, A.H., Silvernail, J.F., Brueggemann, P., Rohr, E., \& Hamill, J. (2013). Footfall patterns during barefoot running on harder and softer surfaces. Footwear Science, 5, 39-44.

Hamill, J., Russell, E.M., Gruber, A.H., \& Miller, R. (2011). Impact characteristics in shod and barefoot running. Footwear Science, 3, 33-40.

Hanson, N.J., Berg, K., Deka, P., Meendering, J.R., \& Ryan, C. (2011). Oxygen cost of running barefoot vs. running shod. International Journal of Sports Medicine, 32, S401.

Hewett, T.E., Stroupe, A.L., Nance, T.A., \& Noyes, F.R. (1996). Plyometric training in female athletes. Decreased impact forces and increased hamstring torques. American Journal of Sports Medicine, 24, 765-773.

Hewett, T.E., Ford, K.R., Hoogenboom, B.J., \& Myer, G.D. (2010). Understanding and preventing ACL injuries: current biomechanical and epidemiologic considerationsupdate 2010. North American Journal of Sports Physical Therapy, 5, 234-251.

Heino, B.J., \& Powers, C.M. (2002). Patellofemoral stress during walking in persons with and without patellofemoral pain. Medicine and Science in Sports and Exercise, 34, 1582-1593.

Ho, K.Y., Blanchette, M.G., \& Powers, C.M. (2012). The influence of heel height on patellofemoral joint kinetics during walking. Gait \& Posture, 36, 271-275. 
Hortobagyi, T., Havasi, J., \& Varga, Z. (1990). Comparison of two stretch-shortening exercise programmes in 13-year-old boys: non-specific training effects. Journal of Human Movement Studies, 18, 177-188.

Kulmala, J.P., Avela, J., Pasanen, K., \& Parkkari, J. (2013). Forefoot strikers exhibit lower running-induced knee loading than rearfoot strikers. Medicine and Science in Sports and Exercise, 45, 2306-2313.

LaPorta, J.W., Brown, L.E., Coburn, J.W., Galpin, A.J., Tufano, J.J., Cazas, V.L., \& Tan, J. G. (2013). Effects of different footwear on vertical jump and landing parameters. The Journal of Strength and Conditioning Research, 27, 733-737.

Lieberman, D.E., Venkadesan, M., Werbel, W.A., Daoud, A.I., D'Andrea, S., Davis, I.S., \& Pitsiladis, Y. (2010). Foot strike patterns and collision forces in habitually barefoot versus shod runners. Nature, 463, 531-535.

Markovic, G. (2007). Does plyometric training improve vertical jump height? (2007). A meta-analytical review. British Journal of Sports Medicine, 41, 349-355.

McClenton, L., Brown, L.E., Coburn, J.W., \& Kersey, R.D. (2008). The effect of short term vertimax vs. depth jump training on vertical jump performance. Journal of Strength and Conditioning Research, 22, 321-325.

Miller, M.G., Herniman, T.J., Ricard, M.D., Cheatham, C.C., \& Michael, T.J. (2006). The effects of a 6-week plyometric training program on agility. Journal of Sports Science and Medicine in Sports, 5, 459-465.

Nigg, B. (2009). Biomechanical considerations on barefoot movement and barefoot shoe concepts. Footwear Science, 1, 73-79.

Piper, T.J., \& Erdmann, L.D. (1998) A 4 step plyometric program. Strength and Conditioning, 20, 72-73.

Powers, C.M., Lilley, J.C., \& Lee, T.Q. (1998). The effects of axial and multiplane loading of the extensor mechanism on the patellofemoral joint. Clinical Biomechanics, 13, 616-624.

Robinson, R.L., \& Nee, R.J. (2007). Analysis of hip strength in females seeking physical therapy treatment for unilateral patellofemoral pain syndrome. Journal of Orthopaedic and Sports Physical Therapy, 37, 232-238.

Romani, W.A., Gieck, J.H., Perrin, D.H., Saliba, E.N., \& Kahler, D.M. (2002). Mechanisms and management of stress fractures in physically active persons. Journal of Atbletic Training, 37, 306.

Rutland, M., O'Connell, D., Brismée, J.M., Sizer, P., Apte, G., \& O'Connell, J. (2010). Evidence-supported rehabilitation of patellar tendinopathy. North American Journal of Sports Physical Therapy, 5, 166-178.

Saluta, J., \& Nunley, J.A. (2010). Managing foot and ankle injuries in athletes. Journal of Musculoskeletal Medicine, 27, 355-363.

Selbie, S.W., Hamill, J., \& Kepple, T.M. (2013). Three-dimensional kinetics. In G. Robertson (Ed.), Research methods in biomechanics (2nd ed., Ch 7, pp.

AQ10 162-170).

Selfe, J., Callaghan, M., Witvrouw, E., Richards, J., Dey, M. P., Sutton, C., \& Turner, D. (2013). Targeted interventions for patellofemoral pain syndrome (TIPPS): classification of clinical subgroups. BMJ open, Epub ahead of print http://bmjopen.

AQ1 1 bmj.com/content/3/9/e003795.abstract. 
Sigward, S.M., Pollard, C.D., \& Powers, C.M. (2012). The influence of sex and maturation on landing biomechanics: implications for anterior cruciate ligament injury. Scandinavian Journal of Medicine and Science in Sports, 22, 502-509.

Sinclair, J. (2014). Effects of barefoot and barefoot inspired footwear on knee and ankle loading during running. Clinical Biomechanics, 29, 395-399.

Sinclair, J., Greenhalgh, A., Edmundson, C.J., Brooks, D., \& Hobbs, S.J. (2013). The influence of barefoot and barefoot-inspired footwear on the kinetics and kinematics of running in comparison to conventional running shoes. Footwear Science, 5, 45-53.

Sinclair, J., Hobbs, S.J., Currigan, G., \& Taylor, P.J. (2013). A comparison of several barefoot inspired footwear models in relation to barefoot and conventional and conventional running footwear. Comparative Exercise Physiology, 9, 13-21.

Smith, J.P., Kernozek, T.W., Kline, D.E., \& Wright, G.A. (2011). Kinematic and kinetic variations among three depth jump conditions in male NCAA division III athletes. Journal of Strength and Conditioning Research, 25, 94-102.

Squadrone, R., \& Gallozzi, C. (2009). Biomechanical and physiological comparison of barefoot and two shod conditions in experienced barefoot runners. Journal of Sports Medicine and Physical Fitness, 49, 6-13.

Stacoff, A., Nigg, B. M., Reinschmidt, C., van den Bogert, A. J., \& Lundberg, A. (2000). Tibiocalcaneal kinematics of barefoot versus shod running. Journal of Biomechanics, 33, 1387-1395.

Wu, Y.K, Lien, Y.H., Lin, K.H., Shih, T.T., Wang, T.G., \& Wang, H.K. (2009). Relationships between three potentiation effects of plyometric training and performance. Scandinavian Journal of Medicine and Science in Sports, 20, 80-86.

van Eijden, T.M., Kouwenhoven, E., Verburg, J., \& Weijs, W.A. (1986). A mathematical model of the patellofemoral joint. Journal of Biomechanics, 19, 219-229.

Waryasz, G.R., \& McDermott, A.Y. (2008). Patellofemoral pain syndrome (PFPS): a systematic review of anatomy and potential risk factors. Dynamic Medicine, 7, 9-23.

Witvrouw, E., Callaghan, M.J., Stefanik, J.J., Noehren, B., Bazett-Jones, D.M., Willson, J. D., \& Crossley, K.M. (2014). Patellofemoral pain: Consensus statement from the 3rd International Patellofemoral Pain Research Retreat held in Vancouver, September 2013. British Journal of Sports Medicine, 48, 411-414.

Zhao, D., Banks, S.A., Mitchell, K.H., D'Lima, D.D., Colwell, C.W., \& Fregly, B.J. (2007). Correlation between the knee adduction torque and medial contact force for a variety of gait patterns. Journal of Orthopaedic Research, 25, 789-797. 